\title{
A DIMENSÃO ECONÔMICA DA TEORIA POLÍTICA ARISTOTÉLICA
}

\author{
Miguel Angel Rossi \\ Patricio Tierno
}

Ainda que tanto a produção bibliográfica quanto o estado da arte no que diz respeito ao pensamento de Aristóteles tenham sido bastante abrangentes ao longo do pensamento ocidental e, inclusive, no oriental, pouca atenção tem sido dada, em comparação com outros aspectos do pensamento do estagirita, ao lugar central que a economia tem no momento de pensar a cosmovisão política aristotélica. Se por um lado, a boa economia deve inscrever-se no âmbito doméstico e não no âmbito público, como aquele próprio da política, por outro lado, a constituição da esfera pública supõe a consolidação de um espaço doméstico pensado no terreno exclusivo da necessidade, ainda que biológica, considerada como registro superado, mas nunca anulado, pelo ideal político aristotélico. Ou seja, o ideal da política como esfera do bom viver. Em outros termos, nossa hipótese gravita em torno da afirmação de que não pode ser constituído um bom viver sem haver assumido a dimensão econômica no terreno das necessidades. De fato, não é casual que Aristóteles pense a propriedade ao mesmo tempo como algo privado, mas com seu uso posto a serviço da comunidade. 
Abordar a problemática da economia em Aristóteles supõe comprometer-se não somente com as questões explicitadas diretamente pelo filósofo, como, por exemplo, o tratamento que Aristóteles dá à economia e à crematística na Política, mas também com assuntos mais sutis e implícitos, como quando o pensador assume uma leitura econômica da política no que diz respeito a regimes políticos específicos (politeia, democracia e oligarquia). Desse modo, nosso artigo atenderá a três aspectos que, por outro lado, estão relacionados entre si.

O primeiro aspecto, o mais visível, e o mérito disso é da hermenêutica arendtiana, é o que diz respeito especificamente ao problema da má crematística, como desconstrução do objeto da política, da vida comunitária ligada ao bom viver. Sem dúvida alguma, o momento agonístico da polis grega que Aristóteles estava presenciando foi motor de muitas de suas reflexões.

180 O segundo aspecto, menos explícito que o anterior, é o que leva o filósofo a vincular, pela primeira vez na história do Ocidente, os regimes políticos com a estrutura social da cidade. A esse respeito se destacam a valoração altamente positiva da politeia, como regime político vinculado ao estamento médio, e a virtude ética, como dimensão deliberativa. Inclusive, pode-se afirmar que Aristóteles foi sensível à problemática da governabilidade.

O terceiro aspecto, o que implica realizar uma leitura dos regimes políticos em chave econômica, erige-se no aspecto central das críticas de Aristóteles à oligarquia. Neste sentido, tornamos explícita outra das hipóteses que procuraremos sustentar em nosso texto: a de que as reflexões mais profundas de Aristóteles se concentram em torno da noção de esfera pública e, por seu intermédio, privilegiam teoricamente a aristocracia, a politeia e a democracia, regimes que não podem ser pensados sem aquela noção. 
Antes de nos focarmos na relação entre política e economia em Aristóteles, acreditamos ser necessário pontuar algumas considerações.

1) Quando falamos de economia devemos evitar todo tipo de anacronismo. É sabido que a antiguidade não teve ideia da economia como ciência autônoma; para isso foi necessário esperar o advento da modernidade. ${ }^{1}$

2) Os problemas que Aristóteles visualiza como problemas econômicos se colocam em uma dimensão absolutamente ética; são pensados a partir do registro da eticidade. Não obstante, aparecem em Aristóteles, questão que Marx observou de forma bastante aguda, algumas das principais noções que formarão parte do repertório definitivo da economia: "valor de uso", "valor de troca", "necessidade", "mercadoria" e "dinheiro". ${ }^{2}$

3) Diferentemente do mundo moderno, que em linhas gerais pode ser interpretado como um mundo cindido, o mundo antigo não conheceu tal cisão. A partir desta perspectiva, seria impossível pensar a política sem a ética e, ambas, sem uma cosmovisão metafísica, quando não teológica. De forma relacionada com tal afirmação, é necessário apontar que as práticas sociais se inscreviam em um universo organicista e também considerar que Platão era tão ou mais organicista que Aristóteles. Isto implica que não podemos diferenciar,

\footnotetext{
${ }^{1}$ A este respeito, Arendt aponta que foi necessário esperar o desenvolvimento e autonomia da sociedade civil, como parte do mundo do privado, para assistir à constituição da economia como ciência. Em seus próprios termos: "[...] nos resulta difícil comprender que, según el pensamiento antiguo sobre estas materias, la expresión economía política habría sido una contradicción de términos: cualquier cosa que fuera económica, en relación a la vida del individuo y a la supervivencia de la especie, era no política, se trataba por definición de un asunto familiar" (Arendt, 2003, p. 42).

${ }^{2}$ Tampouco podemos esquecer, neste ponto, a alta estima que lhe teve Marx: "Las dos peculiaridades de la forma de equivalente analizadas en último lugar se vuelven aun más inteligibles si nos remitimos al gran investigador que analizó por vez primera la forma de valor, como tantas otras formas del pensar, de la sociedad y de la naturaleza. Nos referimos a Aristóteles" (Marx, 1990, pp. 72 e ss).
} 
como acontece na modernidade, um âmbito chamado Sociedade Civil e outro chamado Estado. Somente para dar um exemplo dessa afirmação, poderíamos trazer à baila a noção de justiça. Claro que na antiguidade ela era entendida em termos ontológicos e não sociais. Assim, Platão pensou a ideia de justiça fundamentalmente em relação com as partes da alma, e depois buscou a simetria - de forma espelhada com o organismo social. ${ }^{3}$

4) No caso aristotélico, aprofundar-se no problema da propriedade implica necessariamente aprofundar-se em sua visão ético-política, especialmente no que diz respeito à forte vinculação que o filósofo estabelece entre estrutura social, regimes políticos (basicamente a democracia) e teoria deliberativa. Em particular, tenhamos presente o problema da oligarquia, regime que Aristóteles considera extremamente perverso, sendo pior que ele, somente a tirania; a análise de tal regime é interpretada em termos crematísticos; além da incidência dos metecos, que, ainda que não tivessem direitos de cidadania, possuíam grandes fortunas, o que podia ir contra o ideal da polis como realização da autarquia. Deste modo, a polis podia ser ameaçada pelos interesses tanto da oligarquia interna como por agentes externos que possuíam poder econômico. Voltemos a recordar, pela segunda vez, que Aristóteles está refletindo em um momento agonístico da polis grega.

\footnotetext{
${ }^{3}$ Por oposição, somente com Morus a justiça pôde ser pensada a partir de um registro inteiramente social. A justiça, para Morus, é fundamentalmente uma questão social e deve ser entendida exclusivamente em função das relações sociais que remetem unicamente à sociedade. Assim como a tradição tem apresentado Maquiavel como o pai da Ciência Política, poderíamos sustentar que tem sido injusta com Morus, ao não apresentá-lo como o pai da Sociologia. Com efeito, em Morus aparecem questões que serão retomadas tanto por Durkheim como por Marx. (Explicar um fato social por outro fato social, e não remetermos a explicações extrassociais; entender um fato social como causa ou efeito de outro fato social; a anulação da propriedade privada como princípio de divisão de classes e origem de todos os males, mas lidos na chave social e não metafísica).
} 
Comecemos, pois, com o primeiro ponto, referente à economia antiga. Para tal fim, nos valeremos do marco teórico oferecido por Polanyi em seu célebre A grande transformação (1947).

Um dos pontos significativos do olhar de Polanyi se situa em afirmar que, independentemente da elevação da economia como ciência, fato que, por outra parte, se produz no contexto da modernidade já consolidada, nenhuma sociedade poderia sobreviver a suas próprias necessidades sem uma planificação econômica. Mais ainda, Polanyi sustenta enfaticamente que a própria ideia de mercado não foi alheia às práticas sociais da antiguidade. Não obstante, e aqui está a abismal diferença entre a antiguidade e a modernidade, nas palavras do autor: "[...] con anterioridad a nuestro tiempo nunca existió una economía que aún en principio estuviera controlada por el mercado" (Polanyi, 1947, p. 71).

Ou seja, a instituição do mercado foi marginal no que tange à vida econômica, tanto no mundo antigo quanto no medieval. Dito em outros termos, aqueles mundos foram alheios ao que Marx denominou de fetichismo da mercadoria, posto que, por mais que existisse certo grau de acumulação ou excedente, estes nunca geraram o fenômeno moderno da inversão. É possível recordar que na Idade Média, em pleno regime feudal, o trabalhador ou camponês não estava separado de seus próprios instrumentos de produção.

Polanyi assume a posição de que o âmbito da economia se encontra subsumido completamente às relações sociais. Em consequência, dedica-se a desconstruir o imaginário epocal produzido fundamentalmente no século XIX em torno de uma antropologia do homem econômico, inclinado à ganância e ao interesse (Adam Smith). Assim, argumenta que os bens materiais no mundo antigo não são lidos na chave econômica, mas na social; eles são um meio para legitimar uma posição social no interior da comunidade (clã, tribo, aldeia). 
"El mantenimiento de los lazos sociales, por la otra parte, es fundamental. Primero, porque desdeñado el código aceptado de honor o de generosidad, el individuo se aísla de la sociedad y se convierte en un paria; segundo porque a la larga todas las obligaciones sociales son recíprocas, y su cumplimiento sirve también mejor a los intereses del individuo. Tal situación debe ejercer una presión continua sobre el individuo tendiente a eliminar el interés económico egoísta de su conciencia hasta el punto de no permitirle, en muchos casos (pero en forma alguna en todos), incluso comprender las implicaciones de sus propios actos en términos de interés. Esta actitud es forzada por la frecuencia de las actividades comunales tales como la participación en los resultados de alguna expedición tribal lejana y peligrosa. El valor dado a la generosidad es tan grande, cuando se mide en términos de prestigio social, que simplemente hace que no dé dividendos cualquier comportamiento que no sea el de un completo olvido de sí mismo" (Polanyi, 1947, p. 75).

É relevante o fato de que na percepção de Polanyi a noção de indivíduo não era desconhecida para o mundo antigo. ${ }^{4}$ No entanto, Polanyi é cuidadoso em mostrar a força das práticas sociais coletivas como característica da antiguidade, práticas legitimadas e reguladas por fortes valores sociais. A partir deste ponto de vista, destaquemos que Aristóteles

\footnotetext{
${ }^{4}$ É interessante a postura de Tomás Calvo Martínez, rastreando a questão do indivíduo no pensamento de Sócrates: "En efecto, el recurso a tal idea muestra cómo Sócrates pretende recuperar los lazos que tradicionalmente unían al ciudadano con la polis, lazos debilitados y hasta negados por el individualismo radicalizado de los sofistas. Pero tal recuperación no podía hacerse ya de una manera ingenua, retrocediendo a un estadio previo al surgimiento del individualismo: habría que lograrla desde el reconocimiento de la individualidad y mediante la reflexión. De ahí que la ciudadanía se interprete como compromiso personalizado, reflexivamente asumido, entre el individuo y la polis" (Calvo Martínez, 1997, p. 122).
} 
considera como uma das virtudes centrais dos bons cidadãos a virtude da generosidade, do homem liberal, virtude que não seria entendida sem a referência a um indivíduo atuando em e pelo coletivo. Mas deixemos falar o próprio Aristóteles:

"[...] teniendo cada uno su propiedad privada, permite a sus amigos el uso de algunos de sus bienes y se sirve él mismo de otros comunes. Así, en Lacedemonia todos usan los esclavos de todos, por decirlo así, como si fueran propios, y lo mismo los caballos, los perros y las provisiones del campo que puedan necesitar al atravesar el país. Es claro, por tanto, que es mejor que la propiedad sea privada, pero su utilización sea común. En cuanto el modo de realizarlo, esto es misión propia del legislador" (Aristóteles, 1989, 1.263a).

Observemos que não se trata aqui do homem contratualista do século XVII, que concebe o Estado como uma categoria artificial, sendo os direitos individuais os únicos direitos naturais e/ou absolutos. Nenhum indivíduo grego ou medieval teria pensado que a polis ou a Igreja são categorias artificiais; assim se entende que o pior que poderia acontecer a um indivíduo grego ou medieval, respectivamente, seria o desterro ou a excomunhão.

Da mesma forma, uma das perguntas centrais lançadas pelo autor é: como se assegura a ordem na produção e na distribuição, se, diferentemente da modernidade, não contamos com uma antropologia do trabalho, do esforço e da remuneração? Polanyi enuncia dois princípios substanciais que regiam as condutas. Trata-se da reciprocidade e da redistribuição:

"[...] la reciprocidad funciona principalmente con respecto a la organización sexual de la sociedad, es decir, la familia y el parentesco; la redistribución es efectiva principalmente 
con respecto a todos aquellos que se encuentran bajo un jefe en común y es, por tanto, de un carácter territorial” (Polanyi, 1947, p. 76). ${ }^{5}$

O processo de redistribuição se inscreve dentro do regime político de que se trata. Pode ser a organização tribal, a cidade-Estado, o despotismo oriental, o regime feudal etc.:

"La simetría y la centralidad saldrán al encuentro de las necesidades de la reciprocidad y la redistribución: los modelos institucionales y los principios de conducta son reajustados mutuamente" (Polanyi, 1947, p. 78).

Em conexão com isso, é interessante a perspectiva de Durkheim quando fala do tipo de solidariedade mecânica que caracterizava as comunidades antigas; inclusive a categoria de comunidade será substituída pela de sociedade na moderni186 dade. A ideia do mecânico indica o matiz de espontaneidade automática que ligava segmentos sociais mínimos e homogêneos, pela que se estipulava, também, uma mínima divisão do trabalho vinculada à questão de gênero; assim se complementa, neste aspecto em particular, com a apreciação de Polanyi: as mulheres vinculadas à agricultura e os homens, à casa.

Junto com os princípios de reciprocidade e simetria, características gerais das comunidades antigas, emerge outro princípio específico da polis. Trata-se, utilizando a própria terminologia aristotélica, da administração doméstica. Os gregos se referem a ela como oikonomía, e justamente daqui deriva o termo 'economía'. Polanyi diz, sobre este princípio:

"La necesidad del comercio o de los mercados no es mayor que en el caso de la reciprocidad o redistribución. [...] Aristóteles insiste en que la producción para el uso en

\footnotetext{
${ }^{5}$ Cf., no mesmo sentido, Aristóteles (1989, 1261a e 1320a).
} 
contra de la producción para la ganancia es la esencia de la administración doméstica propiamente dicha: sin embargo, alega, la producción accesoria para el mercado no tiene por qué destruir la autosuficiencia de la administración doméstica mientras la cosecha sembrada con propósito de ganancia también lo hubiera sido para el sustento, como ganado o grano" (Polanyi, 1947, p. 83).

O tema será, então, a invenção do dinheiro, elemento que, em certa medida, rompe a ordem qualitativa de que estão providos todos os produtos tendo em vista o seu uso. Também a troca pode ser pensada a partir desta perspectiva. O problema será, para Aristóteles, a questão da ganância ou do uso pensado com fins exclusivamente econômicos. $\mathrm{Ou}$ seja, divorciados da finalidade suprema que - como repetidas vezes mencionamos - consiste no bom viver da polis.

A partir das premissas de Polanyi, adentremo-nos em algumas passagens-chave da Política, de Aristóteles.

\section{Acerca da contemporaneidade de Aristóteles}

Aristóteles assume a clássica separação - ainda que em conexão - entre a esfera doméstica e a esfera pública ou política. Para o filósofo, a esfera doméstica se encontrava integrada por relações sociais de assimetria, dadas pelos seguintes pares referenciais: senhor-escravo; homem-mulher; paisfilhos. O autor fala assim para caracterizar tal âmbito de poder despótico. Ao inverso, a esfera pública se definia por relações sociais de simetria e isonomia. Aristóteles colocava tal âmbito sob a denominação de 'poder político'. O filósofo insiste em que não pode ser bom governante quem não está disposto a ser bom governado. Daí, em parte, sua preferência pelo estamento médio vinculado estritamente ao melhor regime possível: a politeia e, consequentemente, seu desprezo pelos setores oligárquicos que reduzem o poder político a um poder econômico. 
No que tange à nossa preocupação primária, o eixo teórico que privilegiamos nesta oportunidade é o de como Aristóteles pensou, inclusive prescritivamente, o terreno da economia na esfera doméstica e não na pública. Caberia, então, perguntar-nos quais foram os motivos de Aristóteles para pensar a economia na esfera doméstica e qual o perigo de extrapolação desta na esfera política. A resposta somente poderá ser dada com a alusão à abordagem daquilo que na Política Aristóteles denomina crematística.

"Así pues, hay una especie de arte adquisitivo que es naturalmente parte de la economía: aquella en virtud de la cual la economía tiene a mano [...], los recursos almacenables necesarios para la vida y útiles para la comunidad civil o doméstica. Estos recursos parecen constituir la verdadera riqueza, pues la propiedad de esta índole que basta para vivir bien no es ilimitada" (Aristóteles, 1989, 1.256b).

Previamente à citação acima transcrita, Aristóteles havia estabelecido uma diferenciação entre economia e crematística, em razão de que, sendo a economia uma autêntica arte, não pode senão ocupar-se da correta utilização dos bens domésticos. Em continuação, acrescenta que a crematística, como técnica aquisitiva, pode ser considerada parte da economia. De fato, explicita dois tipos de crematística: uma inscrita e reservada ao terreno doméstico da economia e outra - antinatural - rompendo todo limite e medida. Destaquemos algumas categorias do trecho acima transcrito.

Em primeiro lugar, e como fizemos referência anteriormente, Aristóteles faz estrita alusão à perversão que implica tomar a crematística como uma finalidade em si mesma. Pois, subordinada a crematística à economia, será esta última a que impulsiona e direciona corretamente os recursos armazenáveis ou armazenados. De igual modo, é digno de 
nota o critério não somente descritivo, mas também prescritivo com o qual Aristóteles julga as ciências práticas, entre as quais a política e a ética ocupam um lugar central. Em tal sentido, a crematística deverá estar subordinada à economia que, da mesma forma, poderá ser considerada ciência e, por sua vez, esta última se subordina à política que, por sua parte, é a única, na ordem prática, que Aristóteles considera com autonomia absoluta.

Em segundo lugar, não é por acaso que Aristóteles realça que a persecução destes bens se realiza não somente para viver como também para viver bem, sendo esta a finalidade suprema da política. Tampouco é casual que acentue o critério de 'limitação' que diz respeito não somente às fortunas dos próprios cidadãos como também ao tamanho das respectivas poleis, coincidente com uma visão que exclui as poleis com amplas extensões territoriais, pois é evidente que Aristóteles aposta em uma comunidade onde todos os cidadãos se conhecem, requisito indispensável de uma democracia direta.

Retomando a expressão todo limite e medida, que também nesta segunda instância podemos interpretar como mesura, é importante advertir que ela possui, para o homem medieval e para o antigo, uma profunda carga ontológica, pois transgredir o limite e a medida põe em risco a própria existência de todo ente, o que equivale a dizer, utilizando uma categoria moderna, que se desconstrói a própria essencialidade, com a qual passamos do âmbito do ser ao não ser.

Ainda quando não nos dediquemos aqui ao pano de fundo metafísico que é pressuposto no âmbito da economia em Aristóteles, é importante mencionar que ele se pergunta pelo tipo de entidade que implica, por exemplo, que o dinheiro gere dinheiro: somando-lhe, além disso, o problema da comensurabilidade que faz com que produtos incomensuráveis entre si possam ser quantificados na circulação das mercadorias. Neste aspecto em particular, Aristóteles é muito preciso: ainda que assuma que somente por meio do dinheiro 
podemos intercambiar objetos qualitativamente diferentes, sabe igualmente que tal comensurabilidade nada pode ser além de um artifício, algo antinatural. Por certo, o estagirita não logra dar uma resposta metafísica a tal problema, apesar de assumir que é um autêntico problema metafísico.

Definamos agora a má crematística:

"Hay otra clase de arte adquisitivo que recibe generalmente el nombre - por lo demás justificado - de crematística, para la cual no parece haber límite alguno de la riqueza y la propiedad. Muchos la consideran como idéntica a la antes mencionada, a causa de la proximidad entre ambas, sin embargo no es la misma, si bien tampoco está lejos de ella. Una es natural y la otra no, sino más bien producto de cierta experiencia y técnica" (Aristóteles, 1989, 1.257a).

Aristóteles expõe dois traços que definem essencial190 mente a má crematística: o elemento do antinatural, relacionado a certa técnica, ${ }^{6}$ que acarreta a invenção do dinheiro, e a questão das fortunas ilimitadas, que contrasta com o bom viver da política.

Sobre a base dessas premissas, o estagirita prenuncia, com certa validade contemporânea que nos deslumbra, o que podemos qualificar de aspectos significativos de uma autêntica teoria do valor. Aprofundemo-nos, portanto, em tal teoria.

Aristóteles argumenta que podemos abordar um objeto determinado em função de seu duplo uso: como valor de uso e como valor de troca. Obviamente que a lógica do valor de troca centrada na lógica do dinheiro será aquela que instaure a ideia de uma economia ilimitada. O filósofo considera que um primeiro tipo de troca, por exemplo, a troca que

\footnotetext{
${ }^{6}$ É importante assinalar que Aristóteles classifica o conhecimento em ciência teorética, ciência prática e artes produtivas. Uma técnica (tékhne) se situa, assim, na esfera da produção (poíesis) de objetos úteis ou belos, diferenciada das disciplinas orientadas à ação (práxis) e à contemplação (theoría) .
} 
caracterizou os povos antigos, incluídos os povos bárbaros, é uma consequência natural da não autossuficiência das diferentes comunidades. A partir daí, o estagirita observa que este tipo de troca, para dizê-lo em termos do jovem Marx, não quebra ou rompe o elemento qualitativo de cada objeto em particular. Daí que enfatize que este tipo de troca se situa na ordem da natureza. Em contraposição, a má crematística tem por objetivo unívoco a busca do lucro e a ganância particulares. Mas façamos falar o próprio autor:

"Inventado el dinero a consecuencia de las necesidades del cambio, surgió la segunda forma de crematística, el comercio al por menor que al principio se practicó del modo más simple y después se hizo más técnico cuando la experiencia enseñó dónde y cómo se habían de hacer los cambios para obtener el máximo lucro. Por eso la crematística parece tener que ver sobre todo con el dinero, y su misión parece ser averiguar cómo se obtendría la mayor abundancia de recursos, pues es un arte productivo de riquezas y recursos". (Aristóteles, 1989, 1.257b).

A propósito disso, Moreau (1969) pontua, e concordamos com o estudioso francês, que a instituição da moeda nascida da necessidade de intercâmbios exteriores acarreta uma transformação da própria natureza do intercâmbio. Anteriormente à moeda, o intercâmbio se exercia em forma de troca, limitada às necessidades recíprocas das partes; depois da aparição da moeda, o intercâmbio se libera destas limitações e se divide em compra e venda, e desde esse momento pode estar não somente a serviço das necessidades, como também a serviço de si mesmo, com vistas ao próprio benefício. Encontra-se livre da necessidade natural e é suscetível de um desenvolvimento sem limites.

Não obstante, o autor francês entende que o que Aristóteles questiona não é a invenção da moeda em si mesma, 
já que para ele somente através desta podemos assegurar um intercâmbio de coisas que são entre si incomensuráveis. Justamente será a moeda que as tornará 'comensuráveis'. Claro que Aristóteles insiste em que se trata de uma convenção humana e não de uma ordem natural. Em razão do que, parafraseando Moreau, as perversões econômicas denunciadas por Aristóteles procedem de um uso desregrado da moeda, impulsionado pelo afã de lucro, quando ela não é um meio para facilitar o intercâmbio, uma instituição a serviço dos fins humanos. Como todas as instituições que são criadas pela vontade, obtém seu valor de uso a partir do que se faz com ela, e pode ser, como o idioma, a melhor ou a pior das coisas; pela aplicação do crédito, ela contribui para a cooperação social e para o desenvolvimento da riqueza; mas a especulação conduz à alteração da moeda, os abusos do crédito arruínam a confiança pública, que é o próprio fundamento da comunidade civil.

É digno de notar-se, então, como Aristóteles joga com a oposição do bom viver da polis, onde prima o interesse coletivo, e o máximo lucro que anima o interesse privado e o espírito da avareza. Inclusive em termos irônicos apela à ancestral fábula do famoso Midas que, por sua cobiça, tudo o que tocava se convertia em ouro e, como consequência, morria de fome. Ademais, Aristóteles chega ainda mais longe se perguntando como o dinheiro, elemento antinatural, pode gerar mais dinheiro, adiantando-se magistralmente ao que em nossos dias chamamos de capitalismo financeiro.

Por último, Aristóteles faz referência ao tipo humano - hoje poderíamos dizer psicológico - que aqueles que se dedicam compulsivamente à crematística encarnam:

“[...] pues al perseguir el placer en exceso, procuran también lo que puede proporcionarle ese placer excesivo, y si no pueden procurárselo por medio de la crematística, lo intentan por otro medio, usando todas sus facultades 
de un modo antinatural; lo propio de la valentía no es producir dinero, sino confianza, ni tampoco es lo propio de la estrategia ni de la medicina, cuyos fines respectivos son la victoria y la salud. No obstante, algunos convierten en crematística todas las facultades, como si el producir dinero fuese el fin de todas ellas y todo tuviera que encaminarse a ese fin" (Aristóteles, 1989, 1.258a).

Tanto a administração doméstica como a crematística, dependente da primeira, dizem respeito ao problema da propriedade em geral (ktésis, ousía). A propriedade é, sabemos, uma parte da casa, já que "sem as coisas necessárias são impossíveis a vida e o bem-estar" (Aristóteles, 1989, $1.253 \mathrm{~b})$. Tal como se dá nas artes com respeito aos instrumentos inanimados, o mesmo ocorre com o subordinado na execução de sua função. Por isso, assim como a propriedade é um amontoado de instrumentos, também o escravo (doúlos) é uma possessão animada que opera como um instrumento anterior a outros instrumentos. A distinção, consequente, prossegue até a base: produção e ação diferem especificamente; dá-se o nome de instrumento ao meio de produção, por exemplo, um tear, do qual se extrai algo mais que seu uso, e de possessão ao instrumento prático, como um vestido ou uma cama, que são usados tendo em vista uma ulterior possibilidade de atuação. $\mathrm{O}$ objeto como possessão é, em consequência, uma parte, e como tal depende inteiramente de sua condição. Tal condição é, pois, a condição do escravo - "um subordinado para a ação" (Aristóteles, 1989, 1.254a) -, que se submete, por natureza, à vontade do senhor. Um parágrafo interposto na metade do raciocínio nos anuncia o papel futuro da técnica e nos permite compreender, na era da cidade grega, o notável talento de Aristóteles para pensar a escravidão na perspectiva de um plano estrutural e funcional (Aristóteles, 1989, 1.253b-1.254a): 
"Si todos los instrumentos pudieran cumplir su cometido obedeciendo las órdenes de otro o anticipándose a ellas, como cuentan de las estatuas de Dédalo o de los trípodes de Hefesto, de los que dice el poeta que entraban por sí solos en la asamblea de los dioses, si las lanzaderas tejieran solas y los plectros tocaran solos la cítara, los maestros no necesitarían ayudantes ni esclavos los amos" (Aristóteles, 1989, 1.253b-1.254a).

Apesar de que a relação entre o senhor e o escravo responda a suas respectivas posições dentro da estrutura de relações do oikos, pode-se falar de uma ciência do senhor e outra do escravo como saberes agregados a essa condição. Dessa maneira, a ciência do senhor consistirá em saber servir-se dos escravos, dando as ordens daquilo que o escravo, dentro dos afazeres domésticos, terá de saber fazer. Enquanto isso, o senhor estará livre dos condicionamentos da necessidade para poder dedicar-se a "politizar" ou a "filosofar".

No entanto, não devemos passar ao largo das opiniões daqueles que se voltaram para o problema da escravidão examinando-o em sua face organizativa geral. Um argumento definitivo e de caráter justificador tem em Olof Gigon o seu mais conhecido precursor. Transcrevemos seu juízo fundacional:

"De ningún filósofo antiguo poseemos textos tan explícitos sobre el problema de la esclavitud como de Aristóteles. Se puede considerar esto como un elemento de realismo con el que el filósofo intenta justificar las realidades fundamentales de la sociedad griega. En esto se puede también reconocer una forma peculiar de su contraposición a Platón, que habla de la esclavitud sólo raramente y de pasada: el problema en general apenas le ha interessado" (Gigon, 1965, pp. 243-283). ${ }^{7}$

\footnotetext{
${ }^{7}$ As sociedades antigas eram escravistas. Nelas, uma parcela importante da população se sujeitava a um regime de serviços e trabalhos forçados em virtude de uma
} 
Para além da pretensão de Aristóteles por justificar, Gigon corretamente aponta que o filósofo fundamenta a escravidão no marco mais amplo da economia da cidade. Assim, a constatação empírica chave é a da indispensabilidade de uma força de trabalho servil para realizar as tarefas necessárias, como condição de possibilidade do homem livre dedicado a uma função superior. Ademais, como entrevira certa vez Marx, o "realismo" de Aristóteles o impulsionou, de modo natural, a aceitar uma grande desigualdade das ocupações e, em consequência, a situação de vida dos homens, em nome da manutenção do "modo de produção" da antiguidade.

Mas Gigon não leva em conta que Aristóteles analisa a escravidão como peça da engrenagem social, como instituto privado que faz da gratificação do ócio (skholê) a pedra angular da liberdade política. Na verdade, recorre a uma descrição das posições e atividades econômicas dos diferentes estratos para captar com sutil clarividência os princípios de dominação da ordem social básica que motivam e se diferenciam do princípio político de governo. Dois comentadores que comungam com o estudioso alemão, García e Jiménez, acusam Aristóteles de formular uma tese viciada e circular, mas, paradoxalmente, se desfazem deste preconceito e descobrem o vigor de sua argumentação sistemática:

“[...] sería ilusión creer que con la desaparición nominal de la esclavitud ha desaparecido el problema que él plantea con lucidez: la relación entre el trabajo necesario y el ocio fundamental para la realización como persona humana de quien, auténticamente, quiere llamarse libre" (García Gual e Pérez Jiménez, 1994, pp. 31-32).

privação total de direitos cívicos e autonomia pessoal. O único texto filosófico com que contamos sobre o tema está constituído pelos capítulos 4-7 do livro I da Política. Contudo, não colocamos aqui o problema da escravidão no mundo clássico ou, inclusive, na evolução social das cidades gregas, mas tão-somente sua inserção na teoria política (e econômica) de Aristóteles. 
As críticas posteriores são passíveis de uma classificação bastante segura (cf. Wolff, 1999, pp. 96-102). Três atitudes básicas em relação à escravidão em Aristóteles podem ser apontadas: uma primeira de indignação e pasmo, que pensa ser incompreensível como um pensador tão lúcido e universal pôde ter preconizado uma instituição aberrante; as outras duas atitudes, diferentemente, cultivam a crítica filosófica. Em um extremo, a de inspiração kantiana, baseada na opinião de que as implicações normativas do conceito de natureza impedem a Aristóteles toda crítica moral e política. No extremo oposto, a marxista, segundo a qual o conceito de natureza desempenha, notoriamente, a função de uma ideologia, um discurso legitimador da exploração que as classes dominantes exercem sobre as dominadas.

Wolff propõe, ao invés, que o texto seja abordado a partir de seu interior, e convida à crítica histórico-filológica. Pretende com isso sobrepor-se ao peso da opinião desfavorável 196 que, no final das contas, viu na teoria da escravidão do estagirita uma espécie de cegueira, seja de índole moral, seja de índole histórica. "Mas, afinal, devemos condenar Aristóteles? Em primeiro lugar, é preciso lê-lo” (Wolff, 1999, p. 102).

Uma vez mais nos deslumbra a contemporaneidade deste grande pensador, pois nos mostra, para além das interpretações e das críticas, como, diante de um mundo fragmentado como o que está acontecendo com a derrocada da polis grega, tudo parece ser presa de uma lógica quantificada, em que, inclusive, aqueles valores sociais que representaram as notas essenciais da comunidade política aparecem, ainda que incorramos em um anacronismo, sob o domínio de uma razão instrumental. A partir daí, Aristóteles mostra o esgotamento das funções inerentes a cada arte, como é, por exemplo, a arte da medicina, cujo telos natural é a cura do doente e não a maximização do interesse privado, convertendo, consequentemente, o dinheiro em um telos antinatural de tal atividade. 
Por outra parte, como se deixa notar no tema da escravidão, não devemos esquecer que, em muitos aspectos, Aristóteles representa o espírito tradicional do universo grego; por exemplo, e em coincidência com Platão, assume uma teoria segundo a qual o excesso está vinculado às paixões, que devem sujeitar-se ao governo da razão. Por certo, e para além do fato de que Aristóteles ponha a democracia acima da oligarquia (de modo inverso a Platão na República), de todas as formas, tais regimes são tratados por ambos os filósofos como regimes impuros e, consequentemente, se conectam com a parte apetitiva da alma que se torna hegemônica diante da parte racional. Portanto, trata-se da figura do homem intemperante, que - a partir de sua intemperança - optará sempre pelo interesse particular em detrimento do interesse coletivo; pois ao não obedecer ao logos, à razão, perde o sentido da universalidade que, em termos políticos, podemos designar de 'bem comum'.

Aristóteles insiste em que o que possibilita a existência da comunidade como tal é a existência de vínculos de confiança (amizade). Pois, do contrário, o agir político, na condição de deliberação comunitária, perderá sua razão de ser. Recordemos que a exigência de toda dimensão deliberativa é revisar nossos próprios pressupostos à luz dos pressupostos dos demais interlocutores, disposição que supõe certo grau de abertura em relação às posturas racionais dos outros.

Outro dos grandes temas vinculados à nossa preocupação teórica primordial reside no entrecruzamento que, pela primeira vez na história do Ocidente, o filósofo efetua entre democracia (em sua forma correta, politeia) e estrutura social. Deste modo, o estagirita traria à agenda contemporânea uma categoria que podemos ressignificar a partir da noção de governabilidade. Entremos, agora, nessa perspectiva.

A partir da Política pode-se diferenciar um critério demarcatório entre a melhor forma ideal de governo (monarquia/ aristocracia) e a melhor forma de governo possível, em estrita 
referência à politeia (mescla de formas de governos impuros - democracia e oligarquia -, mas tomando os seus melhores aspectos). Ao considerar somente os elementos nobres dos regimes impuros, Aristóteles situa a politeia como uma aristocracia do estamento médio. Acreditamos ser pertinente esclarecer que não é nossa intenção entrar na explicação e esclarecimento pormenorizados dos regimes de governo em Aristóteles. Mas, ao contrário, fincar o pé nos aspectos sociológico-políticos e filosóficos da politeia e sua incidência na problemática da governabilidade.

Ao falar de sociológico, queremos ressaltar a alusão e a legitimação que Aristóteles efetua de um ethos constituído majoritariamente pelo estamento médio, que suporia, na linguagem política, uma ideia profunda de governabilidade. Ao acentuar o aspecto filosófico, o fazemos com referência à importância que Aristóteles outorga à racionalidade prática como fonte de moralidade coletiva, vinculada ao 198 sentido comum, precondição do sentido comunitário, e a uma teoria do sujeito deliberativo. Mas destrinchemos tal esquema teórico.

"Consideraremos ahora cuál es la mejor forma de gobierno y cuál es la mejor clase de vida para la mayoría de las ciudades y para la mayoría de los hombres, sin asumir un nivel de virtud que esté por encima de personas ordinarias, ni una educación que requiera condiciones afortunadas de naturaleza y recursos, ni un régimen a medida de todos los deseos, sino una clase de vida tal que pueda participar de ella la mayoría de los hombres y un régimen que esté al alcance de la mayoría de las ciudades" (Aristóteles, 1989, 1.295a).

Como pode ser observado na citação, já encontramos o critério demarcatório indicado anteriormente, a saber, averiguar qual é o melhor regime possível. Antes de tudo, é 
sugestivo advertir como para os antigos um regime político é, em essência, uma forma de vida, razão pela qual sempre se fala do homem democrático, tirânico ou, melhor ainda, da alma (também como princípio vital coletivo) democrática, oligárquica etc.

A frase aristotélica: "sem assumir uma virtude que esteja acima das pessoas comuns", merece certas reflexões. Um primeiro matiz mostra a relação entre ética e política, pois se trata de um regime político animado pelo exercício da virtude. O segundo, certamente relacionado com o primeiro, consiste em mostrar que é uma virtude ao alcance da maioria; tratar-se-ia, por conseguinte, do que em termos aristotélicos denominamos virtude ética e não dianoética.

Tenhamos presente que Aristóteles entende por virtude dianoética aquelas virtudes puramente racionais, sendo a sabedoria, própria da vida contemplativa, a virtude suprema. Da mesma forma, tais virtudes estariam conectadas à episteme teórica, cujos objetos de estudo são os entes necessários e eternos, que escapam ao âmbito da contingência. Assim, Aristóteles situa neste âmbito e tipo de saber os entes metafísicos (motor imóvel), os entes matemáticos e os entes daquilo que hoje poderíamos dizer que conformam as ciências naturais.

Para estes tipos de estudos (os puramente especulativos) seria requerido um tipo de virtude especial que, por outro lado, escaparia ao alcance da grande maioria, concretamente virtudes dianoéticas.

Por virtude ética, Aristóteles também distingue virtudes e faculdades racionais, mas desta vez aplicadas a legislar o plano do desejo, próprio de todo âmbito ético. Ou seja, o exercício racional que regula o aspecto sensitivo.

"Es, por tanto, la virtud (ética) un modo de ser selectivo, siendo un término medio relativo a nosotros, determinado por la razón y por aquello que decidiría el hombre 
prudente. Es un medio entre dos vicios, uno por exceso y otro por defecto[...]" (Aristóteles, 1993, 1.107a).

Se a virtude dianoética se conecta com a episteme teórica, a virtude ética se conectará com a episteme prática. É interessante destacar como Aristóteles inicia uma tradição teórica na qual cada episteme se define de acordo com seu próprio objeto de estudo.

A episteme prática, na qual Aristóteles inclui como a mais importante a política, toma como núcleo de interesse as ações humanas, mas ao contrário dos objetos das ciências contemplativas, que são imutáveis e portanto necessárias, as ações humanas revestem o selo do mutável ou cambiante. Diferentemente de Platão, Aristóteles crê que pode haver uma ciência da contingência e esta é a política. Precisamente, é através de uma teoria da ação humana de caráter contingente que o filósofo de Estagira pensará a noção de con200 senso, sempre sujeita à revisão e a configurações específicas de cada polis em particular. "Deliberamos, entonces, sobre lo que está en nuestro poder y es realizable, y eso es lo que resta por mencionar" (Aristóteles, 1993, 1.112a).

Dito de outra maneira, aquilo que depende de nós pode ressignificar-se a partir da ideia de autarquia, e justamente Aristóteles destaca o caráter da factibilidade, concretamente o espaço do possível. Por isso, Aristóteles exclui da deliberação, exercício centrado na prudência (phrónesis) como racionalidade prática, tanto os loucos como os néscios.

"La deliberación tiene lugar, pues, acerca de cosas que suceden la mayoría de las veces de cierta manera, pero cuyo desenlace no es claro y de aquellas en que es indeterminado. Y llamamos a ciertos consejeros en materia de importancia, porque no estamos convencidos de poseer la adecuada información para hacer un buen diagnóstico" (Aristóteles, 1993, 1.112b). 
Resumamos, então, os elementos centrais de uma teoria da deliberação. Em primeiro lugar, o sujeito político não reside em uma teoria da iluminação reservada a uns poucos, mas - como dissemos antes - na grande maioria. Por esta razão, Aristóteles fala de virtude moral, em relação à política, e não de virtude dianoética, a qual é pensada para a contemplação filosófica. ${ }^{8}$

Em segundo lugar, tal sujeito político somente pode ser compreendido em termos de deliberação, dado que ao tratar-se de ações contingentes, por sua própria especificidade estrutural, escapam ao terreno das verdades absolutas.

Em terceiro lugar, Aristóteles considera que a virtude moral suprema é a justiça e esta se entende estritamente em termos comunitários; mais ainda, é a virtude que dá coesão e existência ao próprio corpo da polis.

Restaria mencionar brevemente o aspecto pelo qual Aristóteles é o primeiro na história do pensamento ocidental que une estrutura social e regime político, com magistral clareza para nos mostrar que não pode haver politeia possível sem a conformação de um ethos cujos integrantes não sejam indigentes, nem material nem culturalmente falando.

"En efecto, si se ha dicho con razón en la Ética que la vida feliz es la vida sin impedimentos de acuerdo con la virtud, y que la virtud consiste en un término medio, necesariamente la vida media será la mejor, por estar el término medio al alcance de la mayoría. Y estos mismos criterios serán necesariamente los de la virtud o maldad de la ciudad y del régimen, porque el régimen es la forma de vida de la ciudad. Ahora bien, en toda ciudad hay tres elementos: los muy ricos, los muy pobres y, en tercer lugar, los intermedios

\footnotetext{
${ }^{8}$ A contemplação filosófica, a vida mais digna a que pode aspirar um homem, de acordo com Aristóteles, possui uma significação valorativa similar à atribuída por Platão, tanto que, para ambos os filósofos, a vida contemplativa está reservada somente para alguns.
} 
entre unos y otros; y puesto que hemos convenido en que lo moderado y lo intermedio es lo mejor, es evidente que también cuando se trata de la posición de los bienes de la fortuna la intermedia es la mejor de todas, porque es la que más fácil obedece a la razón” (Aristóteles, 1989, 1.295a).

Aparece primeiramente a temática da felicidade, bem supremo da ética e da política, do homem e da polis. Felicidade que somente pode estar situada no exercício da virtude. Neste sentido, já distinguimos dois tipos de virtude: a dianoética e a ética. Portanto, podemos falar de dois tipos de felicidade: a da vida contemplativa, própria da episteme teórica, cuja virtude suprema é a contemplação ou sabedoria, e a da vida na polis, cuja virtude suprema será a justiça. É importante mencionar que a alusão ao termo médio (mesótes) faz referência direta às virtudes éticas e, depois, o próprio Aristóteles entrelaça tal conceito com o estamento médio. Inclusive não 202 titubeia em afirmar que os melhores legisladores, como o foi Sólon, também pertenciam ao estamento médio. Por isso, novamente temos que recordar que um regime é antes de tudo uma forma de vida. Nisto, daria a impressão que Aristóteles se adianta a pensadores como Habermas e Rawls. Pois o funcionamento de uma autêntica democracia deliberativa necessita a ação de sujeitos providos de uma racionalidade prática, de uma moralidade que habilite os próprios interlocutores, como agentes responsáveis na tomada de decisões e aptos para a faculdade do juízo, presentes em instituições como as assembleias e os tribunais gregos. Um sujeito que resolva o problema, enraizado no tempo, da indigência. Aqui Aristóteles é muito claro: as virtudes são antes de tudo virtudes da polis, virtudes sociais. Noção que será retomada por todo o pensamento medieval e pelo humanismo renascentista. Não se pode formar um ethos virtuoso sem que se tenham satisfeitas as necessidades básicas e se tenha tido a oportunidade de formar o próprio caráter, dentro do qual o estagi- 
rita privilegia o papel da educação (paideia). Este é um dos problemas básicos das oligarquias, já que se as crianças não são educadas desde a mais tenra infância, dificilmente conseguem submeter sua parte irracional aos ditames da razão. Daí que sustente que estão acostumados a mandar, mas não a obedecer a seus mestres, extrapolando tal têmpera, na vida adulta, à conformação de um poder despótico.

Finalmente, e a título de breve conclusão, cremos que chegamos a uma constelação de categorias conceituais que se remetem mutuamente. Pois, ainda que Aristóteles considere como regimes ideais a monarquia e a aristocracia, também é indubitável que todas as referências à melhor forma de vida, pelo menos para a maioria dos cidadãos, apontam para o melhor regime possível: um regime em que a crematística se subordina à economia, organizada sobre o sistema da escravidão, e ambas, à política; um regime em que os cidadãos potencializam o sentido comum como precondição do sentido comunitário e possuem fortunas médias por meio das quais se ativa o exercício da generosidade; esse regime, assim descrito, não pode ser outro que não o da politeia democrática.

\section{Miguel Angel Rossi}

é doutor em Ciência Política (USP), pesquisador do Conicet, Argentina, professor de Teoria Política e Filosofia (UBA)

\section{Patricio Tierno}

é professor de Ciência Política na Universidade de São Paulo

\section{Referências bibliográficas}

ARENDT, H. 2003. La condición humana. Buenos Aires: Paidós.

ARISTÓTELES. 1989. Política. Madrid: Centro de Estudios

Constitucionales. 1993. Ética Nicomaquéa. Madrid: Gredos. 1994. Política. Tradução, prefácio e notas de Carlos García Gual e Aurelio Pérez Jiménez. Madrid: Alianza Editorial. 
CALVO MARTÍNEZ, T. 1997. "Sócrates". In: GARCÍA GUAL, C. (ed). Historia de la filosofía antigua. Madrid: Trotta.

GIGON, O. 1965. "Die Sklaverei bei Aristoteles". In: Fondation Hardt. La "Politique" d'Aristote, Entretiens sur l'Antiquité Classique. VandoeuvresGenève, 1965. Tome XI, pp. 245-283.

MARX, K. 1990. El Capital. México, D. F.: Siglo Veintiuno Editores. Tomo I, vol. 1, Livro primeiro.

MOREAU, J. 1969. “Aristote et la monnaie”. Revue des Études Grecques, no 82.

POLANYI, K. 1947. La gran transformación. Buenos Aires: Ed. Claridad.

TAYLOR, C. 2006. Imaginarios sociales modernos. Barcelona: Paidós.

WOLFF, F, 1999. Aristóteles e a política. São Paulo: Discurso Editorial. 


\section{A DIMENSÃO ECONÔMICA DA TEORIA POLÍTICA ARISTOTÉLICA}

MIGUEL ANGEL ROSSI

\section{PATRICIO TIERNO}

O objetivo do artigo é enfatizar o lugar que ocupa a economia na cosmovisão política de Aristóteles, assumindo o pressuposto segundo o qual o filósofo considera a economia como uma dimensão central da mesma forma que uma condição de possibilidade para pensar a comunidade política. Nesse sentido, percorre-se três aspectos de tal problemática. O primeiro aspecto, o mais visível, cujo descobrimento é mérito da hermenêutica arendtiana, é aquele que diz respeito especificamente 234 ao problema da crematística como desconstrução do objeto da política, considerada como vida comunitária ligada ao bom viver. O segundo aspecto é o que conduz o filósofo a vincular, pela primeira vez na história do Ocidente, os regimes políticos à estrutura social da polis. $\mathrm{O}$ terceiro aspecto consiste em realizar uma leitura dos regimes políticos na chave econômica, aspecto central das profundas críticas de Aristóteles à oligarquia. Desse modo, deixa-se explícita outra das hipóteses que se sustenta no texto: a de que as reflexões de Aristóteles se concentram na noção de esfera pública e, por isso, privilegiam teoricamente a aristocracia, a politeia e, inclusive, a democracia.

Palavras-chave: Economia; Política; Crematística; Regimes políticos.

\section{ECONOMICAL DIMENSION OF ARISTOTLE'S POLITICAL THEORY}

The objetive of the article is to emphasize the place of economics in the political cosmovision of Aristotle under the assumption of economics 
as a central dimension and a prerequisite of the philosopher's thinking about political community. In that sense, it covers three aspects of that problematic. The firs aspect, the most visible one, which discovery is merit of Arendtian hermeneutics, attends specifically to the problem of bad chrematistic as a deconstruction of the politics's object, in so far as communitarian life is related to the good life. The second aspect allows the philosopher to relate, for the first time in Western history, the political regimes to the social structure of the polis. The third aspect implies a vision of political regimes in economic terms and is the core of Aristotle's profound criticism of oligarchy. In that way, it makes explicit another assumptiom of this paper: that Aristotle's reflections are concentrated on the notion of public sphere and, for that reason, they privilege theoretically aristocracy, politeia, and even democracy.

Keywords: Economics; Politics; Chrematistic; Political regimes. 